\title{
Chemical Probe
}

National Cancer Institute

\section{Source}

National Cancer Institute. Chemical Probe. NCI Thesaurus. Code C73628.

A small molecule that reacts with a known target in a predictable way, thereby showing location, identification, physiological state, etc. 